\title{
Editorial
}

Clinical Care/Education

Diabetes Metab J 2019;43:763-765

https://doi.org/10.4093/dmj.2019.0247

pISSN 2233-6079 · eISSN 2233-6087

DIABET\&S \& METABOLISM JOURNAL

\section{New Diagnostic Criteria for Gestational Diabetes Mellitus and Pregnancy Outcomes in Korea}

\author{
Kyu Yeon Hur ${ }^{1,2}$ \\ ${ }^{1}$ Division of Endocrinology and Metabolism, Department of Medicine, Samsung Medical Center, Sungkyunkwan University School of Medicine, Seoul, \\ ${ }^{2}$ Department of Health Sciences and Technology, Samsung Advanced Institute for Health Sciences \& Technology, Sungkyunkwan University, Seoul, Korea
}

Gestational diabetes mellitus (GDM) is defined as any degree of glucose intolerance first detected during pregnancy regardless of the degree of hyperglycemia [1] although this definition has serious limitations [2]. The age of a mother, pre-pregnancy body mass index, the amount of obesity, family history, and weight gain during pregnancy are GDM-related factors [3]. It is a common medical complication in pregnancy and is associated with adverse maternal and neonatal outcomes $[4,5]$ as well as lifelong risk of obesity and diabetes in both mother and child later in life [6,7]. Treatment of GDM has been shown to reduce adverse outcomes [8]. So, it is of great importance to diagnose this condition early and manage adequately to prevent adverse outcome.

It is estimated that GDM affects around 7\% to $10 \%$ of all pregnancies worldwide $[7,9,10]$. However, comparing GDM prevalence between countries has been confounded by differing sets of diagnostic criteria. The absence of universal gold standards for screening of GDM has led to heterogeneity in the identification of GDM, thereby impacting the accurate estimation of the prevalence of GDM, related health outcomes as well as their health costs.

In 2010, the International Association of the Diabetes and Pregnancy Study Groups (IADPSG) recommended universal screening of all pregnant women with the 75-g oral glucose tolerance test (OGTT) [11] based on the results of the international prospective Hyperglycemia and Adverse Pregnancy Outcomes (HAPO) study [12]. The American Diabetes Asso- ciation (ADA) in 2011 [13], the Endocrine Society [14] and the World Health Organization (WHO) [15] in 2013 accepted the IADPSG guidelines. However, the American College of Obstetricians and Gynecologist (ACOG) refuse to accept the IADPSG criteria in $2013[16,17]$ and has retained the two-step procedure using the thresholds of the National Diabetes Data Group (NDDG) [18] or Carpenter and Coustan [19] criteria. After then, the ADA in 2014 revised to agree both ACOG and IADPSG recommendations [20]; the "one-step" 75-g OGTT derived from the IADPSG [11] criteria and the older "twostep" approach with a 50-g (nonfasting) screen followed by a 100-g OGTT for those who screen positive, based on the work of Carpenter and Coustan (CC)'s interpretation [19] of the older O'Sullivan criteria [21]. Table 1 shows different diagnostic criteria of GDM. Currently, the Korean Diabetes Association indorses using both the IADPSG criteria and the CC criteria for the diagnosis of GDM.

This prospective observational cohort study done by Kim et al. [22] is the first study to investigate the number of GDM diagnoses and pregnancy outcomes in Korean women who were diagnosed with GDM by the IADPSG criteria. Between 24 and 28 weeks of gestation, all women screened via the 50 -g glucose challenge test regardless of fasting. Those who had glucose value above $140 \mathrm{mg} / \mathrm{dL}$ underwent diagnostic 75-g 2-hour OGTTs. GDM was diagnosed by the CC criteria. However, 3-hour glucose was not measured and was omitted form the CC criteria in this study. Women diagnosed with GDM by the
Corresponding author: Kyu Yeon Hur (iD https://orcid.org/0000-0002-3065-7252 Division of Endocrinology and Metabolism, Department of Medicine, Samsung Medical Center, Sungkyunkwan University School of Medicine, 81 Irwon-ro, Gangnam-gu, Seoul 06351, Korea

E-mail: ky.hur@samsung.com
This is an Open Access article distributed under the terms of the Creative Commons Attribution Non-Commercial License (http://creativecommons.org/licenses/by-nc/4.0/) which permits unrestricted non-commercial use, distribution, and reproduction in any medium, provided the original work is properly cited. 
Table 1. Diagnostic criteria of gestational diabetes mellitus

\begin{tabular}{|c|c|c|c|c|c|c|c|c|}
\hline & \multirow{2}{*}{ Year } & \multirow{2}{*}{ Steps } & \multirow{2}{*}{$\begin{array}{l}\text { Glucose load, } \\
\text { g }\end{array}$} & \multirow{2}{*}{$\begin{array}{l}\text { No. of abnormal values for } \\
\text { diagnosis }(\geq)\end{array}$} & \multicolumn{4}{|c|}{ OGTT, mg/dL } \\
\hline & & & & & Fasting & $1 \mathrm{hr}$ & $2 \mathrm{hr}$ & $3 \mathrm{hr}$ \\
\hline O'Sullivan & 1964 & 2 & 100 & 2 & 90 & 165 & 145 & 125 \\
\hline NDDG & 1979 & 2 & 100 & 2 & 105 & 190 & 165 & 145 \\
\hline $\mathrm{CC}$ & 1982 & 2 & 100 & 2 & 95 & 180 & 155 & 140 \\
\hline IADPSG & 2010 & 1 & 75 & 1 & 92 & 180 & 153 & - \\
\hline WHO & 2013 & 1 & 75 & 1 & \multicolumn{4}{|c|}{ IADPSG OGTT criteria } \\
\hline \multirow[t]{2}{*}{ ACOG } & 2018 & 2 & 100 & 2 & \multicolumn{4}{|c|}{ NDDG OGTT criteria } \\
\hline & & 2 & 100 & 2 & \multicolumn{4}{|c|}{ CC OGTT criteria } \\
\hline \multirow[t]{2}{*}{ ADA } & 2020 & 1 & 75 & 1 & \multicolumn{4}{|c|}{ IADPSG OGTT criteria } \\
\hline & & 2 & 100 & 2 & \multicolumn{4}{|c|}{ CC OGTT criteria } \\
\hline
\end{tabular}

OGTT, oral glucose tolerance test; NDDG, National Diabetes Data Group; CC, Carpenter and Coustan; IADPSG, International Association of Diabetes Pregnancy Study Group; WHO, World Health Organization; ACOG, American College of Obstetricians and Gynecologist; ADA, American Diabetes Association.

CC criteria were managed according to the standard clinical practice guidelines. However, women who would be diagnosed by the IADPSG criteria but not by CC criteria were not managed as GDM patients and only had routine prenatal obstetric care. They stratified participants into three groups of (1) women with no GDM by either the IADPSG criteria or the CC criteria (no GDM group); (2) women exclusively diagnosed with GDM by the IADPSG criteria and not by the CC criteria (IADPSG GDM group); and (3) women diagnosed with GDM by the CC criteria (CC GDM group). The IADPSG criteria increased the incidence of GDM by nearly three-fold (the incidence of GDM was $2.1 \%$ according to CC criteria, and additionally $6.2 \%$ by the IADPSG criteria). Compared to the no GDM group, women in the IADPSG GDM group had an increased risk of preeclampsia, and neonates had an increased risk of large for gestational age, macrosomia, and neonatal hypoglycemia. This study had several limitations; the IADPSG criteria were not applied as a one-step approach and a 75-g OGTT was used instead of a 100-g OGTT in CC criteria.

In summary, IADPSG universally increased the prevalence of GDM. When applying the IADPSG criteria in Korea, the prevalence of GDM must be increased and it will be necessary to evaluate the cost effectiveness of treating GDM diagnosed by IADPSG criteria. Women with a past history of GDM had a $50 \%$ increased risk of developing type 2 diabetes within 7 to 10 years of pregnancy [23] and a seven-fold increased risk of developing it compared to normal glucose tolerance of pregnancy [24]. Further, it will also be necessary to investigate postpar- tum risk of diabetes or prediabetes according to IADPSG diagnostic criteria in Korea.

\section{CONFLICTS OF INTEREST}

No potential conflict of interest relevant to this article was reported.

\section{REREFENCES}

1. Basri NI, Mahdy ZA, Ahmad S, Abdul Karim AK, Shan LP, Abdul Manaf MR, Ismail NAM. The World Health Organization (WHO) versus The International Association of Diabetes and Pregnancy Study Group (IADPSG) diagnostic criteria of gestational diabetes mellitus (GDM) and their associated maternal and neonatal outcomes. Horm Mol Biol Clin Investig 2018;34:20170077.

2. Huvinen E, Koivusalo SB, Meinila J, Valkama A, Tiitinen A, Rono K, Stach-Lempinen B, Eriksson JG. Effects of a lifestyle intervention during pregnancy and first postpartum year: findings from the RADIEL study. J Clin Endocrinol Metab 2018; 103:1669-77.

3. Yang SH, Kim C, An HS, An H, Lee JS. Prediction of gestational diabetes mellitus in pregnant Korean women based on abdominal subcutaneous fat thickness as measured by ultrasonography. Diabetes Metab J 2017;41:486-91.

4. Wendland EM, Torloni MR, Falavigna M, Trujillo J, Dode MA, Campos MA, Duncan BB, Schmidt MI. Gestational diabetes 
and pregnancy outcomes: a systematic review of the World Health Organization (WHO) and the International Association of Diabetes in Pregnancy Study Groups (IADPSG) diagnostic criteria. BMC Pregnancy Childbirth 2012;12:23.

5. Farrar D, Simmonds M, Bryant M, Sheldon TA, Tuffnell D, Golder S, Dunne F, Lawlor DA. Hyperglycaemia and risk of adverse perinatal outcomes: systematic review and meta-analysis. BMJ 2016;354:i4694.

6. Kim SY, Sharma AJ, Callaghan WM. Gestational diabetes and childhood obesity: what is the link? Curr Opin Obstet Gynecol 2012;24:376-81.

7. Xiong X, Saunders LD, Wang FL, Demianczuk NN. Gestational diabetes mellitus: prevalence, risk factors, maternal and infant outcomes. Int J Gynaecol Obstet 2001;75:221-8.

8. Landon MB, Spong CY, Thom E, Carpenter MW, Ramin SM, Casey B, Wapner RJ, Varner MW, Rouse DJ, Thorp JM Jr, Sciscione A, Catalano P, Harper M, Saade G, Lain KY, Sorokin Y, Peaceman AM, Tolosa JE, Anderson GB; Eunice Kennedy Shriver National Institute of Child Health and Human Development Maternal-Fetal Medicine Units Network. A multicenter, randomized trial of treatment for mild gestational diabetes. N Engl J Med 2009;361:1339-48.

9. Ferrara A. Increasing prevalence of gestational diabetes mellitus: a public health perspective. Diabetes Care 2007;30 Suppl 2:S141-6.

10. Nguyen CL, Pham NM, Binns CW, Duong DV, Lee AH. Prevalence of gestational diabetes mellitus in Eastern and Southeastern Asia: a systematic review and meta-analysis. J Diabetes Res 2018;2018:6536974.

11. International Association of Diabetes and Pregnancy Study Groups Consensus Panel, Metzger BE, Gabbe SG, Persson B, Buchanan TA, Catalano PA, Damm P, Dyer AR, Leiva Ad, Hod M, Kitzmiler JL, Lowe LP, McIntyre HD, Oats JJ, Omori Y, Schmidt MI. International association of diabetes and pregnancy study groups recommendations on the diagnosis and classification of hyperglycemia in pregnancy. Diabetes Care 2010;33:676-82.

12. HAPO Study Cooperative Research Group, Metzger BE, Lowe LP, Dyer AR, Trimble ER, Chaovarindr U, Coustan DR, Hadden DR, McCance DR, Hod M, McIntyre HD, Oats JJ, Persson
B, Rogers MS, Sacks DA. Hyperglycemia and adverse pregnancy outcomes. N Engl J Med 2008;358:1991-2002.

13. American Diabetes Association. Standards of medical care in diabetes: 2011. Diabetes Care 2011;34 Suppl 1:S11-61.

14. Blumer I, Hadar E, Hadden DR, Jovanovic L, Mestman JH, Murad MH, Yogev Y. Diabetes and pregnancy: an endocrine society clinical practice guideline. J Clin Endocrinol Metab 2013;98:4227-49.

15. World Health Organization: Diagnostic criteria and classification of hyperglycemia first detected in pregnancy. Available from: http://apps.who.int/iris/bitstream/10665/85975/1/ WHO_NMH_MND_13.2_eng.pdf(cited 2019 Dec 23).

16. Committee on Practice Bulletins-Obstetrics. Practice Bulletin No. 137: gestational diabetes mellitus. Obstet Gynecol 2013; 122(2 Pt 1):406-16.

17. National Institutes of Health consensus development conference statement: diagnosing gestational diabetes mellitus, March 4-6, 2013. Obstet Gynecol 2013;122(2 Pt 1):358-69.

18. National Diabetes Data Group. Classification and diagnosis of diabetes mellitus and other categories of glucose intolerance. Diabetes 1979;28:1039-57.

19. Carpenter MW, Coustan DR. Criteria for screening tests for gestational diabetes. Am J Obstet Gynecol 1982;144:768-73.

20. American Diabetes Association. 2. Classification and diagnosis of diabetes: standards of medical care in diabetes-2020. Diabetes Care 2020;43(Suppl 1):S14-31.

21. O'Sullivan JB, Mahan CM. Criteria for the oral glucose tolerance test in pregnancy. Diabetes 1964;13:278-85.

22. Kim MH, Kwak SH, Kim SH, Hong JS, Chung HR, Choi SH, Kim MY, Jang HC. Pregnancy outcomes of women additionally diagnosed as gestational diabetes by the International Association of the Diabetes and Pregnancy Study Groups Criteria. Diabetes Metab J 2019;43:766-75.

23. Kim C, Newton KM, Knopp RH. Gestational diabetes and the incidence of type 2 diabetes: a systematic review. Diabetes Care 2002;25:1862-8.

24. Bellamy L, Casas JP, Hingorani AD, Williams D. Type 2 diabetes mellitus after gestational diabetes: a systematic review and meta-analysis. Lancet 2009;373:1773-9. 